LIMA, Cleverton de Barros. Literatura e sofrimento: um olhar médico sobre a 'vida'. História, Ciências, Saúde Manguinhos, Rio de Janeiro, v.20, n.3,

\title{
Literatura e sofrimento:
} um olhar médico sobre a 'vida'

\section{Literature and suffering: a medical perspective on 'life'}

Cleverton Barros de Lima

Doutorando do Programa de Pós-graduação em História/Instituto de Filosofia e Ciências Humanas/ Universidade Estadual de Campinas. Rua Cora Coralina, s/n

13083-896 - Campinas - São Paulo - Brasil cleverton76@gmail.com jul.-set. 2013, p.1025-1040.

\section{Resumo}

Trata da abordagem estética do escritor e médico sergipano Ranulpho Prata, enfatizando as figurações sobre a vida em uma vertente católica do sofrimento no período da Primeira República. O artigo problematiza a ideia de sofrimento resignado que, vinculado à visão política do pensamento católico do Centro Dom Vital, era sugerido às camadas pobres da população brasileira. Essas eram identificadas na obra de Prata pelos imigrantes nortistas da capital federal e pelos habitantes do interior.

Palavras-chave: Ranulpho Prata (18691942); sofrimento; política; literatura; Brasil.

\section{Abstract}

The aesthetic approach of Ranulpho Prata, a Brazilian writer and doctor born in the state of Sergipe, emphasizes figurations about life in the catholic approach to suffering during the First Republic (1889-1930). The article problematizes the idea of resigned suffering, which, combined with the political perspective of the catholic thought of the Dom Vital Center, was recommended for the poorer strata of Brazilian society. They were identified in Prata's work as migrants from the north to the federal capital and inhabitants of the countryside.

Keywords: Ranulpho Prata (1869-1942); suffering; politics; literature; Brazil. 
$\mathrm{O}$ médico Ranulpho Hora Prata (1869-1942) publicou o romance Dentro da vida em 1922 (Prata, 1953). Durante as décadas de 1920 e de 1930, Prata serviu-se da excelente receptividade da obra, que, em linhas gerais, expunha os reveses do narrador, o jovem Bento Luís. Tanto o narrador personagem quanto o autor partilham do mesmo ofício: a medicina (Anderson, Shakleton, 2011). O ponto central do romance é tecido pela relação entre o médico e o sofrimento. Ao narrar a trajetória de Bento, o escritor sergipano expressa uma linha de interpretação a respeito do sofrimento dos pobres e da 'missão' do médico ao lidar com os problemas do abandono político dos que, em sua concepção, mais precisavam de atenção. O problema da narrativa, então, alinha-se aos dissabores vivenciados pelas classes pobres marginalizadas no Brasil das primeiras décadas do século XX. Seguindo esses indícios, procuro compreender as linhas teóricas e políticas bem como as representações do sofrimento no pensamento do escritor médico.

Ranulpho Prata ${ }^{1}$ nasceu no município de Lagarto, no estado de Sergipe. O município tem uma tradição intelectual vertiginosa, tendo sido berço de Sílvio Romero, Aníbal Freire, Laudelino Freire e Joel Silveira. O caso de Ranulpho Prata não foi diferente: ao longo da sua trajetória exerceu os ofícios de jornalista, professor, contista e médico, inserindo-se no contexto intelectual brasileiro. Iniciou o curso de medicina na Bahia, mas concluiu-o no Rio de Janeiro, em 1920. Morou no interior de São Paulo, onde atuou como médico. Também residiu em Santos, onde obteve substrato para tessitura de sua obra mais conhecida, Navios iluminados, datada de 1937 (Prata, 1996). A escrita de Ranulpho Prata aproxima-se do cotidiano da carreira médica, exercida por longos anos, símbolo do subtítulo do romance Dentro da vida: narrativa de um médico de aldeia (Prata, 1953).

O período de formação no Rio de Janeiro foi marcado pela amizade com o escritor Lima Barreto (Sevcenko, 2003). Os autores trocaram cartas, por meio das quais é possível comprovar o interesse que compartilhavam em relação ao problema social brasileiro, simbolizado na classe pobre da emergente República. Após a saída de Ranulpho Prata do Rio de Janeiro para trabalho médico em Mirassol, interior de São Paulo, continuou a amizade com o autor de Recordações do escrivão Isaías Caminha (1995). As trocas epistolares atestam a ida de Lima Barreto até Mirassol, tema de crônicas que foram reunidas no volume Marginália (Barreto, 1961b, p.47). O afeto entre os dois escritores esteve no centro da produção do romance Dentro da vida. Antes de publicar o romance, o primeiro esboço foi o conto dedicado a Lima Barreto, como expressa o trecho epistolar:

Li teu conto no jornal, o qual tiveste a bondade de me dedicar. Muito obrigado. Está bom e próprio para "jornal". Podias, porém, detalhar um pouco mais, entrar mais nas causas da transformação do doutor Fagundes, chic, elegante, um pouco pedante, no simplório "Seu" Fagundes da botica e do gamão. Tente fazer um romance daí que terás feito obra curiosa. Estudarás bem a influência da roça, a adaptação à vida dela, com os seus encantos e defeitos, de um "acadêmico" tout à fait, como dizias ainda não há muitos meses (Barreto, 1961a, p.244).

Após a morte de Lima Barreto, Ranulpho Prata o homenageou na tese apresentada no concurso para cátedra de professor do Atheneu Pedro II, em Aracaju, o que atesta a expressiva afinidade e respeito pelo amigo (Prata, 1926). 
Durante o período de estudos médicos no Rio de Janeiro, Ranulpho Prata trabalha intensamente com ficção; nessa ocasião escreve as primeiras narrativas, um acervo ainda inexplorado pela historiografia. ${ }^{2} \mathrm{Em} 1918$ publicou a coletânea de contos $O$ triunfo, em seguida lançou os romances Dentro da vida ([1922] 1953), A longa estrada (1925a) e O lírio na torrente (1925b). Na década de 1930, o médico volta à cena literária com os livros Lampião (1934) e Navios iluminados ([1937] 1996). Essa última obra é a mais difundida e analisada pela crítica literária, pois se aproxima da temática do romance social, uma vez que relata a vida dos nordestinos e estrangeiros na cidade de Santos no final dos anos 1920 e princípio da década de 1930. O enfoque da obra é a questão do trabalho e da sobrevivência desses personagens na cidade portuária. Sobretudo a vida de penúria do protagonista na cidade de Santos, o baiano de Patrocínio do Coité, José Severino de Jesus. Oriundo do sertão baiano, Severino, como tantos outros migrantes do Norte e Nordeste, vai à procura de trabalho no Macuco, bairro portuário de Santos. Lá encontra um ambiente desagregador, de pobreza e fome, elementos estéticos do romance social de 1930. Portanto, nele se encontra a expressividade da migração de nordestinos para cidades, em que se notabiliza a perspectiva urbana nos romances de escritores nordestinos (Pereira, 2008).

Assim como nos decênios de 1920 e 1930, a denúncia social da precariedade e da marginalização dos pobres tornou-se objeto dos romances sociais. Chamo atenção do leitor para o caso do escritor Amando Fontes e do seu livro Os corumbas, datado de 1933, que traça a trajetória de uma família que foge para a cidade, em razão da seca de 1905 no interior de Sergipe. Eles migram para a capital, Aracaju, onde passam a trabalhar nas fábricas de tecidos, indústria em ampla ascensão naquele período. Na cidade, a família desagrega-se em virtude de várias tragédias, dentre as quais se destacam a morte da filha mais nova devido a uma tuberculose não tratada de forma adequada; a prisão do filho Pedro por participar do movimento operário e, por fim, a perdição moral das filhas mais velhas que, ao envolver-se sexualmente com os parceiros, perdem-se na degradante prostituição (Lima, 2009).

A digressão nos auxilia na compreensão do quanto o problema social esteve em discussão nas primeiras décadas do século passado entre escritores oriundos da região Norte e Nordeste do país. Ranulpho Prata empenha-se, nesse sentido, em seus romances e contos, no diagnóstico dos impasses da sociedade brasileira no período turbulento da Primeira República (1889-1939) até a ascensão do governo Getúlio Vargas (1930-1945). Os temas de sua preferência estiveram relacionados à vida dos imigrantes no Rio de Janeiro; em seguida, o interesse recaiu sobre o êxodo de nordestinos fugidos da penúria para o Sudeste; e, por fim, a figuração de Lampião, o que demonstra as inquietações do médico, mobilizado por temas de ampla relevância política.

No final do século XIX, os médicos passam a ser respeitados como intelectuais. Segundo, Micael Herschmann (1994, p.43; ênfase do original), no momento de "transição da Monarquia para República, observou-se a proeminência da figura do médico 'à condição de intelectual prestigiado' e da medicina à posição de um saber 'regenerativo' e crucial para o país". O saber médico, então, alcançou status de autoridade, pois compreendia-se que "caberia ao homem de direito apenas ser um assessor que colocaria sob forma de lei o que o perito médico (ou mesmo o cientista) já diagnosticara e, com o tempo, trataria de sanear" (p.46). Em geral, esses médicos pretendiam normatizar a sociedade, com a produção de uma 'raça sadia' e 'pura'. No campo 
médico brasileiro surgiram então duas grandes escolas, a Faculdade de Medicina do Rio de Janeiro e a da Bahia. Na capital federal, dois médicos são figuras emblemáticas, Oswaldo Cruz e Carlos Chagas; ambos sustentaram uma prática médica de combate às epidemias. Enquanto isso, na Bahia, Nina Rodrigues focava o doente e as doenças transmissíveis hereditariamente. Ele optou pelas teses eugênicas, que se tornaram centrais nos debates polêmicos sobre a "identidade nacional" e "nação" nos anos 1920 (Herschmann, 1994, p.50).

É pertinente salientar que Ranulpho Prata estudou nas duas faculdades mencionadas. Quanto à filiação da proposta médica de seu livro, é percebível uma conotação do médico oriundo da Faculdade de Medicina do Rio de Janeiro. Não há uma consagração da condição eugênica do brasileiro, o negro não é colocado em uma condição na qual representa periculosidade, ideia inscrita nas teorias eugênicas em voga. Ao contrário, o narrador enfoca, sobretudo, as epidemias que assolavam o país, como, por exemplo, a malária e a tuberculose. Isto é, a linha de observação de Ranulpho Prata destaca sua formação médica na capital federal.

No romance Dentro da vida, o projeto literário de Ranulpho Prata era esboçar um quadro do que ele acreditava ser a 'vida'. Em sua acepção, a vida decorre das experiências de sofrimentos vividos pelos pobres, no ambiente do trabalho e na família. Opção literária que o levou a tratar da vida de um menino pobre e órfão, filho desgarrado, que chega ao topo da carreira intelectual, ao formar-se médico e trabalhar no interior de Minas Gerais. Como não pensar na vida do autor que, após a formatura, trabalhou durante boa parte da vida em Mirassol, interior de São Paulo?

Localizo, ainda, uma filiação de Ranulpho Prata à estética política proposta pelo intelectual sergipano Jackson de Figueiredo (1891-1928). Recorro à dedicatória da tese "A renascença das letras em França”, de Ranulpho a Lima Barreto: o grande 'humilhado e luminoso', um dos maiores romancistas brasileiros, o criador inimitável de Isaías Caminha e Policarpo Quaresma. Homenagem de quem o admirou e amou (Prata, 1926, p.I; ênfase do original). As palavras humilhado e luminoso referem-se a um dos livros de Jackson de Figueiredo, publicado em 1921, sobre o poeta mineiro Uriel Tavares. Jackson afirma a respeito do poeta de Muzambinho: "Não sendo romancista, não dispondo mesmo de imaginação, tem o autor a paixão das almas, maximé daquelas que viu e vê passarem despercebidas da grande maioria dos homens" (Figueiredo, 1921, p.7). O enfoque da 'vida' em Ranulpho Prata vincula-se diretamente às pessoas que não são protagonistas centrais, ou seja, os alijados pelas contingências e sobressaltos, exatamente o ponto de vista de Jackson de Figueiredo (1917).

Por isso, acredito em uma inspiração católica nessa leitura que dialoga com o projeto político do Centro Dom Vital, do qual Ranulpho Prata fazia parte, até, como amigo de Jackson de Figueiredo, como veremos a seguir.

\section{Sutilezas do olhar sobre a'vida'}

No romance Dentro da vida, o protagonista Bento Luís rememora a vida difícil, repleta de infortúnios, mas que, ao termo, se revelou uma trajetória vitoriosa. Ele venceu os problemas familiares, as dificuldades da formação acadêmica e de ingresso no mercado de trabalho médico. A perda prematura dos pais levou o garoto a viver nas ruas do Rio de Janeiro, em 
uma situação de abandono e de marginalidade. É clara a estratégia política de Ranulpho Prata em denunciar de forma contundente o problema social dos menores abandonados na capital federal das primeiras décadas do século passado. O médico, então, instaura o olhar do "observador social" que salienta os problemas na urbe (Faure, 2008, p.13-55), ou seja, a preocupação da medicina social diante da condição de vida na cidade moderna (Bresciani, 2008 , p.10). Esse olhar de denúncia tem tonalidades intensas por se agregar à retórica do sofrimento defendida pelo escritor. O que certamente ratifica a escolha de Ranulpho Prata pela epígrafe do romance Dentro da vida entendida como 'efeito de real' (Barthes, 1984) da medicina e de sua missão. As palavras são de Miguel Couto (citado em Prata, 1953, p.VII): "Não vos esqueçais, então, de que se toda medicina não está na bondade, menos vale separada dela. Por menor e mais humilde que seja a sua condição, o homem pode realizar alguma coisa de grande e de útil na vida".

A figura do médico está associada à bondade e, mesmo, à opção pelos pobres; isto é, esse profissional acredita na missão piedosa em favor das vidas sofridas. Ao afiliar-se às propostas do médico sanitarista e político Miguel Couto (1865-1934), Ranulpho Prata crê, como ele, que a medicina é a segunda mãe da humanidade. Nesse sentido, Miguel Couto (Secretaria..., s.d.) faz um paralelo interessante a respeito da relação entre a medicina e a guerra:

Uma é a preservação da humanidade, a outra o extermínio; uma é bondade piedosamente organizada, a outra maldade cruelmente instituída; uma vive de dedicação e do altruísmo; a outra se nutre da rapinagem e da carniça; numa entra o homem com a força divina do seu ser, na outra o homem com seus instintos atávicos de fera; uma é a vida, a outra é a morte.

Nesses termos, o interesse do médico pelos sofrimentos dos pobres alia-se à piedade 'organizada' na escrita de Ranulpho Prata. Suas figuras estão associadas à penúria e à escassez de recursos para sobrevivência na cidade. O narrador onipresente, Bento Luís, discorre sobre as circunstâncias de sua escalada social, de menino órfão ao sonhado posto de médico.

Historicamente, uma longa tradição une os campos da medicina e da literatura. No século XIX, o escritor francês Émile Zola $(1971 ; 1995)$ aproximou a atividade médica ao exercício literário no denominado romance experimental, em que se configurou a prática da vertente naturalista na França. Essa proposta de Zola está vinculada aos ideais de retorno à natureza e, por consequência, a uma maior aproximação da inteligência humana à vida. O escritor francês se referia, via o método experimental do médico Claude Bernard, na obra Introduction à l'étude de la médecine expérimentale, de 1865, à base sólida da escrita ficcional, na qual aproxima a perspectiva médica à feitura do romance. A função do escritor estava fincada na ideia de análise pormenorizada do ser humano, da sociedade e da moral pelo método científico; eis o projeto estético do autor francês, concretizado na publicação do romance Thérèse Raquin ([1867] 2007), obra inaugural do naturalismo.

Moacyr Scliar descreveu com propriedade a relação existente entre esses dois campos. Para ele, é uma prática corriqueira do campo literário a interação comum ao campo da medicina, bem como a outros ramos do conhecimento. Scliar (2000, p.246) comenta a aproximação:

a medicina se vê como ciência. Fala a linguagem da ciência e portanto se situa no âmbito da cultura científica. De outra parte, a doença e a prática médica são temas frequentes 
na obra de poetas, romancistas, ensaístas. Textos clássicos o exemplificam: A morte de Ivan Illich, de Leon Tolstoi, fala do penoso confronto com o término da existência e a problemática relação médico-paciente nesta situação; $A$ montanha mágica, de Thomas Mann, tem como cenário um sanatório de tuberculosos; O alienista, de Machado de Assis, é uma sátira à psiquiatria autoritária do século dezenove.

Dyonélio Machado (1895-1085), outro médico-escritor, colabora com essa tradição ao tratar do problema da loucura no romance O louco do Cati (2003). A obra figura as agruras do período varguista, conferindo um olhar sobre o tipo de vida que poderia se viver (Faria, 2009).

No caso do autor sergipano, a figuração da vida é exposta do ponto vista do personagem Bento. Essa é sinônimo do sofrimento vivenciado pelos pobres e marginalizados das primeiras décadas do século passado, na cidade do Rio de Janeiro da Primeira República, onde viviam o cenário de intensificação da atividades fabris, frutos do novo cenário, em que os homens são condenados ao cotidiano fabril em longas horas de trabalhos com exíguo retorno pecuniário. A família do protagonista sofre a desagregação 'terrificante' da vida citadina.

A tristeza e a desolação do personagem estão vinculadas aos ressentimentos que nutre em relação à figura paterna. Tem do pai uma imagem de derrota e tristeza pulsante, pois o mesmo o fez sofrer, e também a sua mãe. Esse sentimento de repulsa recrudesceu quando da demissão de seu pai, ao ser preso e acusado de envolvimento direto no movimento anarquista. Antes de migrar para o Rio de Janeiro o pai, Francisco Matias, ou Chico Matias, era seringueiro na Amazônia - região que, no texto, é denominada pelo narrador de inferno ${ }^{3}$-, onde sofreu emboscada pelo patrão, que lhe desferiu um tiro. A despeito do estado de violência, Chico Matias conseguiu se recuperar desse episódio fatídico e decidiu buscar uma nova vida na capital do Brasil, o sonhado Rio de Janeiro.

Ao ser despedido, "instala em sua casa uma oficina de sapateiro, continuando, porém, com a mesma vida desordenada que levava na fábrica. E não tardou em atascar-se no vício, no álcool e no jogo" (Prata, 1953, p.15). O narrador conclui asseverando que o pai participou do anarquismo como movimento, mas que nem sabia o que era. No romance, o anarquismo é figurado como movimento contestatório das precárias condições de trabalho nas fábricas, especialmente a parca remuneração e o espaço insalubre (Lopreato, 2000). No período, eram recorrentes as prisões de trabalhadores que se envolviam em algum tipo de manifestação por melhoria das condições de trabalho.

A leitura do narrador remete à visão política do povo alienado ou ao 'povo sem memória', recorrente no imaginário político até hoje, do qual está ausente qualquer força de organização (Bresciani, 2004, p.424). É uma postura típica do discurso conservador das primeiras décadas do século XX que ainda reverbera no imaginário social contemporâneo.

Não é somente esse aspecto que subsiste; há uma leitura recorrente de que as ideias estavam "fora de lugar", conforme salientou Maria Stella Bresciani (2007, p.142) ao analisar os denominados intérpretes do Brasil e, em especial, Oliveira Vianna, intelectual lido de forma assídua em boa parte do século passado:

Entre os primeiros intérpretes e seus interpretadores mantém-se uma mesma linha argumentativa, que me leva a indagar se estaria na facilidade explicativa proporcionada pelo lugar-comum da carência, da falta de moto próprio e de capacidade criativa da população brasileira, a adesão quase universal (devo enfatizar o quase) pela atual 
produção acadêmica a teoria da mimesis, afirmação da incapacidade intelectiva que nos levaria a "importar ideias" eternamente?

É indispensável sublinhar que essa leitura política é corriqueira na historiografia e na literatura, principalmente quando pensamos no livro de Ranulpho Prata. Aspecto delineado na postura de Miguel Couto (1933) citado na epígrafe do romance Dentro da vida, no qual afirma que o que faltava ao povo brasileiro era educação.

Certamente, a postura é contrária ao determinismo racial do século XIX, portanto, adversa às conjecturas de pensadores como Gobineau. Para Miguel Couto, o povo só poderia ser aperfeiçoado mediante a instrução, que colocaria o Brasil entre as nações proeminentes (Couto, 1933, p.142). Essa ideia está esboçada na proposta do escritor Ranulpho Prata, ao recorrer ao pensamento de Miguel Couto e, assim, apostar na educação como a redenção do pobre. Na proposta desse pensador higienista, existe uma crítica ao abandono das classes pobres, seguida por uma negativa ao determinismo racial como fonte do problema (Couto, 1932, p.82). Com isso, eles reafirmaram as incisivas explicações do atraso da nação, colocando-se como saneadores do país. A resolução do problema do atraso ficaria, portanto, sob a responsabilidade dos médicos, ao utilizar a educação como forma de obter um povo saudável.

Acrescido ao problema do povo inculto, afirmava-se a questão do abandono e de seu desconhecimento. No início do século, ao cobrir a Guerra de Canudos, o escritor Euclides da Cunha levantou, em seu livro Os sertões (2000), a tese do esquecimento do 'povo do norte', tido como desconhecido. Durante as décadas seguintes cristalizaram-se as representações de que era imperioso 'conhecer o país'. Márcia Naxara (1998, p.16) afirma, em relação às ideias de Euclides da Cunha, que, "em meio às ambiguidades provocadas pelo dilema do atraso brasileiro versus a civilização, utilizou para nós, brasileiros, a expressão de vivermos um quase exílio paradoxal dentro de nossa própria terra".

Não é por acaso que o subtítulo do romance Dentro da vida elege o olhar do "médico de aldeia". Bento adentra o sul de Minas Gerais, mais precisamente nas proximidades de São Sebastião do Sul, rumo à cidade de São Tomás de Aquino, a fim de exercer seu ofício em um lugar desconhecido, no interior do país; longe, portanto, do centro urbano carioca onde se criou. Os aspectos marcantes para o jovem médico são a tristeza e a pobreza da região forrada pelo cerrado. Dela, a paisagem transmuta-se para as lavouras, "mostrando em agradáveis perspectivas o verde-chumbo dos longos cafezais" (Prata, 1953, p.37). Na carta, datada de janeiro de 1921, trocada com Lima Barreto, Prata (1961, p.245) reafirma esse sentimento de desolação do médico no interior do Brasil, justamente na época em que trabalhou em Mirassol:

nada posso fazer no interior, num ambiente que asfixia e mata. E, ademais, o tempo é pouco para dar alívio físico ao jeca sofredor. E é assim, meu caro e ilustre homem de letras, que um moço como eu que sempre ambicionou uma vida superior, uma vida de espírito, consuma todo o seu tempo em curar tracomas, amarelão e disenterias! ... Não se pode imaginar o que é a clínica do interior, clínica de casebres. Andam de braços em casa do nosso caboclo, numa funesta e desoladora parceria, a miséria e a moléstia. Verdadeiros quadros de romance meus olhos têm visto.

Encontrar a diversidade, e mesmo a miséria dos humildes esquecidos no interior do país, valoriza os anseios do recém-formado, que não buscava glória ou riqueza. Sua felicidade 
encontra-se no fato de que "ser feliz é ser humilde e ser simples, tendo no coração um sentimento grande de fraternidade" (Prata, 1953, p.39). A fim de melhorar a vida dos sofredores das aldeias, Bento resolve investir em laços de maior proximidade, simpatia e amor com as agruras desses desafortunados. Havia um peso, uma responsabilidade, que era a de cuidar dos desprotegidos para quem a vida, em vez de ser mãe, tornara-se uma impiedosa madrasta. Ardia no íntimo o amor altruísta por aqueles que encarnavam os sofrimentos, manifestando os males no corpo e no espírito.

\section{Pobreza e piedade, o crivo religioso}

Dentro da Vida, pequena obra-prima de sentimento.

Figueiredo (1926, p.91)

Essas palavras do mentor do Centro Dom Vital sintetizam o objetivo do médico Ranulpho Prata em trazer ao público os sentimentos vinculados aos personagens pobres. No plano geral da obra, a vida do casal migrante do Norte do país, Francisco Matias e a mãe (o narrador não cita o nome), revela as paixões que parte da intelectualidade nutria quanto às condições dos trabalhadores pobres nas cidades. A fábrica e as novidades da vida na cidade moderna tornaram-se um desafio para essas figuras que foram submetidas à nova ordem fabril (De Decca, 1996). No contexto histórico das primeiras décadas do século XX, evidenciouse "o sentido de desenraizamento expresso na perda de identidade social e de formas de orientação multisseculares", que "aparece de forma recorrente, elaborando a imagem de uma crise de proporção e conteúdos inéditos" (Bresciani, 1985, p.37). Os indícios de crise na trama do romance Dentro da vida trazem sintomaticamente o desenraizamento da família como ponto-chave.

A referência perceptível do desenraizamento está associada à figura materna. O escritor sergipano consagra a vertente estoica na figura compassiva e sofredora da mãe. Ela se associa à imagem cristã do sacrifício ${ }^{4}$, ao mesmo tempo em que se vincula ao mundo sem conflito que certamente é uma proposta política do pensamento conservador (Romano, 1997). Ressalta ainda o uso de metáforas que estão associadas à semântica cristã de sofrimento aproximado à postura de resignação (Ricouer, 2000). Na descrição figurativa da mãe feita pelo "médico de aldeia", Bento Luís manifesta essa faceta:

Minha mãe era frágil, gasta nos trabalhos da fábrica, onde vivia desde os quinze anos, descorada, de pequena estatura, só tendo como atrativo a suave mansidão das suas feições menineiras, o que, de certo, meu pai nunca percebera.

Há criaturas que vêm ao mundo dentro de tal passividade e estoicismo, que dão a ideia de receberem o sofrimento como uma graça divina.

Minha mãe era desse número.

Desde o dia maldito do seu casamento até a hora em que expirou no hospital, com os olhos meigos fitos na irmã de caridade, jamais articulou um queixume, nem tampouco a agitou movimento altivo de revolta.

Toda ela era um doloroso feito de humildade e fraqueza (Prata, 1953, p.14-15). 
Emudecer diante dos problemas é uma atitude embasada na tradição do cristianismo ocidental. Uma moldura comum no pensamento cristão, consubstanciada, na tradição do cristianismo, na figura sacra do sacrifício expiatório, mas, sobretudo, do pensamento romântico, como na máxima do filósofo alemão Friedrich Schiller, ao afirmar que "as grandes almas sofrem em silêncio". Infere-se, portanto, que as peculiaridades do escritor Ranulpho Prata vinculam-se aos princípios retóricos sustentados pelo culto ao sofrimento contido e sem rebelião, caracterizado na proposta política de amplitude reacionária.

A figuração da mãe do personagem Bento sugere igualmente a compaixão. ${ }^{5}$ Ela é qualificada com atributos de uma pessoa sem atrativos e totalmente inexpressiva, restrita aos sentimentos e paixões conferidas aos marginalizados. Nesse tocante, a resignação diante dos problemas da vida é o que a torna encantadora, especialmente pela mansidão 'estoica' não reconhecida nem valorizada pela figura paterna desde o início do matrimônio, como afirma o narrador. A conduta da mãe piedosa a torna uma figura devotada ao casamento, até porque suporta estoicamente as diversas traições do marido. O desalento do narrador não está na figura materna, mas na condição deficitária do pai em relação aos cuidados com a família.

Tal estoicismo (Pereira, 1993), a despeito de sua historicidade, propõe a aceitação dos acontecimentos, das dores e temores como forma de encarar o sofrimento passivamente, anulando, assim, qualquer paixão. Deve-se viver, para essa escola do pensamento filosófico, de acordo com 'a lei natural'. E o natural é fruto inequívoco da 'razão divina', instaurada, assim, no viver virtuoso como projeto político, de modo que o vício é a sua antítese. O ideal para o estoico é a 'apatia', que significa 'indiferença' às demandas da vida, ou seja, a anulação emocional no cumprimento das obrigações do convívio social e que pode ser resumido na seguinte epígrafe estoica: "suporta e abstém-te".

Observo nessa mesma linha de pensamento uma associação ao pensamento católico romano do autor sergipano. Em um dos poucos registros de Ranulpho Prata, é perceptível a aproximação da vertente católica ligada ao Centro Dom Vital. O Centro Dom Vital foi criado em meados da década de 1920 por Jackson de Figueiredo. Tornou-se uma referência no pensamento político nas décadas seguintes, especialmente, pela divulgação de suas ideias na revista $A$ Ordem, no Rio de Janeiro (Cabral, 2011).

Existe registro da proximidade de Jackson de Figueiredo com Ranulpho Prata. Na troca epistolar entre Lima Barreto e Prata na década de 1920, o autor carioca comenta que procurou Jackson de Figueiredo com intuito de saber informações do amigo que estava em São Paulo. A carta, datada de 3 de janeiro de 1921, diz o seguinte: "Meu caro Ranulpho, não sei onde estás, mas o Jackson me disse, anteontem, que andavas por São Paulo, nos cafundós. Li teu conto no jornal, no qual tiveste a bondade de me dedicar. Muito obrigado" (Barreto, 1961a, p.244).

A aproximação intelectual entre Ranulpho Prata e Jackson de Figueiredo é notória no pronunciamento da solenidade de inauguração do Centro Dom Vital em Sergipe. Ele afirma, então, que Sergipe era o "berço do nosso grande Jackson", por isso, "não podia, de nenhum modo, quedar-se indiferente à obra grandiosa de fé e de combate, que foi o maior e o melhor sonho de sua inteligência". Esse sonho de Jackson, havia se expandido e "germinado" por outros estados do país, segundo Prata. A relação com o amigo é ingrediente para confirmar sua autoridade como conferencista: “Ah! Como nós, os seus amigos, nos sentimos jubilosos, 
vendo que cada dia ele está mais vivo, e sempre no nosso lado, imperecível na beleza e grandiosidade de sua obra" (Prata, 1933, p.1). Enfim, a participação na inauguração do Centro Dom Vital apresenta um autor próximo e respeitoso ao legado do pensamento de Jackson de Figueiredo.

Aqui, junto aos amigos de infância de Jackson, na vizinhança destes sítios melancólicos onde ele passou os seus dias nervosos de menino, do menino que havia de ser mais tarde o ser de exceção, tão útil ao Brasil e à "Fé", como que sentimos mais perto de nós, mais na nossa intimidade, a viver conosco todas as horas.

Bem sabeis que estais a receber um humilde e velho soldado da fé e da Igreja. Ao enfileirar-me nas vossas hostes, repito o juramento feito a mim mesmo, há mais de lustro, de combater o bom combate.

Sob o patrocínio do espírito de Jackson, que sinto pairar nesta sala como um pássaro de asas de luz, enchendo os nossos corações de uma saudade doce e consoladora, vou dar início a minha palestra.

O assunto - o sofrimento - é sacerdotal, e eu me desculpo de o inutilizar (Prata, 1933, p.2).

Com essas palavras Ranulpho Prata inicia sua conferência, a convite do padre Moisés Ferreira, uma das figuras do Centro Dom Vital e diretor do periódico católico no estado de Sergipe. Na época, ele residia em Santos, uma das cidades que adotou por boa parte da vida; sua aproximação com o estado natal também estava associada ao fato de ser o detentor da sétima cadeira da Academia Sergipana de Letras.

O mote da conferência foi o sofrimento humano como motor das experiências (Prata, 1933). Para ele, que se considera "humilde e velho soldado da fé e da Igreja", cumpre deixar claro, desde o preâmbulo, a reverência ao pensamento de Jackson de Figueiredo - que havia falecido em 1928 -, bem como circunscrever o tema ao âmbito sacerdotal. Ranulpho Prata (1933, p.3-4) delimita com precisão a notória relação entre sofrimento e crença, um depende da outra:

Na vida toda cheia de incertezas, de ilusões e de imprevistos, só há de certo e fatal o sofrimento.

Do berço ao túmulo é o companheiro inseparável do homem.

Não se lhe despega da ilharga, como uma sombra triste.

A história do sofrimento é a história mesma da humanidade.

O nascimento é um ato de sofrimento grandioso e duplo. Sofre quem dá a vida e sofre quem a recebe.

Depois, sem mais nos abandonar, vai ele nos seguindo, palmilhando conosco toda a subida alegre da montanha.

Ao longo da apresentação, Ranulpho Prata define a relação entre sofrimento e vida. Ele crê plenamente no sofrimento como o 'alicerce fundo', a 'base sólida' e, por fim, como fluxo da vida. É por meio desse sentimento que os poetas e escritores fundamentam seus textos e obras. Para respaldar o ponto de vista a respeito do sofrimento, recorre aos poetas Gonçalves Dias, Cruz e Souza, Cleomenes Campos, entre outros. As questões que os uniram são a visão articulada pelo sofrimento e a humildade, o que se verifica na escrita do poeta Cleomenes 
Campos, ao reiterar preferência pelo lirismo à pobreza em seu livro de poesia publicado em 1931, que tem por título Humildade:

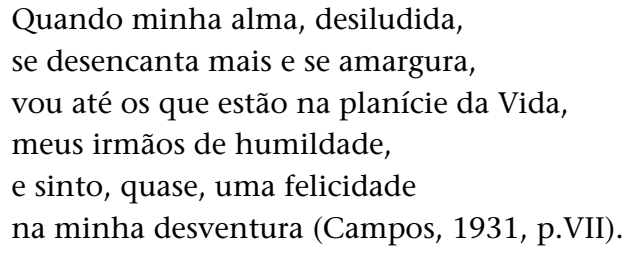

Nas primeiras páginas da obra, Cleomenes Campos utilizou uma epígrafe bastante conhecida do escritor britânico Oscar Wilde: "A humildade no artista é sua franca aceitação de toda experiência". Certamente, a ideia do escritor inglês é muito elucidativa da perspectiva do pensamento estético e político de escritores brasileiros como Ranulpho Prata. A humildade é o padrão artístico soberano para o escritor que, nesse ponto de vista estético, atém-se às experiências da vida e do sofrimento como inseparáveis do percurso da humanidade.

Outro detalhe relevante é que, segundo essa proposta estética, os seres humanos não podem jamais alterar sua condição de sofrimento. Ela não pode ser vencida por ninguém, pois não existe saída, a vida não possibilita alternativa. No decorrer da vida, o sofrimento sempre impelirá o homem a voltar ao seu estado 'natural' do sofrer contínuo: "Não nos movimentamos sem sofrer, sem encontrarmos a cada minuto obstáculos, onde esbarramos com desgosto e mágoa. Tudo é fonte de sofrimento. Por toda a parte o vemos" (Prata, 1933, p.6).

E não é preciso questionar o porquê do sofrimento, pois, segundo Ranulpho Prata (1933, p.9), ele vem de Deus. Ao pensar o sofrimento, em uma acepção 'sacerdotal', o escritor sergipano cita o texto do Antigo Testamento, Jó 2: 11-13. No trecho bíblico aludido, os amigos de Jó, Elifaz, Bildade e Zofar, "foram visitá-lo no monturo e o viram a raspar as chagas, imerso na sua grande dor, nada puderam dizer. Sete dias e sete noites ali ficaram, mudos, sem achar palavras de consolação" (Prata, 1933, p.8).

Ainda ilustra a questão ao recorrer à história da "jovem, linda e rica" de vinte anos, a "bela francesa" Marie Konstantinowna Bashkirtseff (1858-1884) (Prata, 1933, p.8-9). Na realidade, ela não era francesa, mas da nobreza russa, nascida na Ucrânia, e havia passado quase todo tempo de sua breve vida viajando pela Europa. Em temporada na França, estudou pintura em Paris, sendo a pintura uma das áreas na qual sua atuação é reconhecida ainda hoje, embora parte de suas obras tenha sido destruída pelos nazistas durante a Segunda Guerra Mundial. O diário deixado pela artista - que começou a ser escrito aos 13 anos -, juntamente com as telas que restaram, justificam sua notoriedade, bem como o espanto da sociedade francesa por sua morte prematura, de tuberculose, aos 25 anos (Leujeune, 1997). A doença, que ceifou a vida de muitos artistas, deixou todo o mundo moderno em estado de tensão (Sontag, 2007).

Ranulpho Prata utiliza a tragédia de Bashkirtseff para questionar o motivo do sofrimento humano. A resposta estaria nos desígnios de Deus, que, sendo bom, infligia aos homens essa prova. Trata-se, na realidade, para Ranulpho Prata, de um paradoxo "aparente", pois "quanto mais amada" uma pessoa é, "maior sofrimento deve receber" (Prata, 1933, p.9). Existe nesse tipo de teorização uma aparente ambiguidade, pois, para a vertente do catolicismo romano, o sofrimento estaria mais restrito à questão do pecado original de Adão e Eva, enquanto que, para Ranulpho, ele é infligido pelo fato pessoal de importância, ou seja, a singularidade. 
Os personagens de Ranulpho Prata estão, por assim dizer, inscritos na visão do sofrimento como matriz explicativa. Por isso, sua obra encaminha-se para a explicação do sofrimento como foco central. A narrativa converge sempre para os instantes de sofrimento e de ressentimentos vividos pelo personagem narrador, Bento Luís.

Após a morte dos pais, o órfão encontra acolhimento ao lado do padrinho, o engenheiro doutor Gomes, residente em um palacete do bairro de Botafogo. A família do engenheiro era composta por dona Rosa, a esposa, e mais dois filhos: a mais nova, Marta, de cinco anos, e "um rapazinho de quinze, o Alfredo" (Prata, 1953, p.20). Outra componente da família era Rita, menina trazida pelo doutor Gomes quando trabalhou em um açude no estado do Ceará.

Ranulpho sugere as peculiaridades da piedade por meio do acolhimento nada familiar de Bento e Rita pelo doutor Gomes. Por piedade, o engenheiro trouxera Rita do Ceará, mas que se entenda a completa condescendência deste quanto às arbitrariedades da esposa, visto que os acolhidos não eram tratados da mesma forma que os filhos do casal. O narrador relata o lado hostil de dona Rosa, que imprimia censuras e repreensões ao convívio diário no palacete. Ela o persegue acintosamente, por meio da recriminação constante para que ele trabalhe, não permitindo assim que se sinta parte da família. Logo, o garoto não se diferenciava dos demais empregados. O único detalhe que conferia distinção residia na forma de pagamento: os empregados recebiam dinheiro, e Bento era agraciado com as roupas usadas por Alfredo.

Em outro momento, a hostilidade de dona Rosa volta-se para Rita por meio de castigos severos. Quando estava brincando com Marta, dona Rosa "puxava as orelhas, lembrando-lhe as obrigações a cumprir". O episódio corriqueiro gerou em Bento o que posso sinalizar como a tese central do escritor Ranulpho Prata a respeito da 'vida':

Num movimento muito natural em mim, comecei o olhar mais para aquela companheirinha infeliz, sem pais, sem afeto, como que atirada por mão cruel dentro da vida. Fiz-me seu amigo, cativei-lhe a confiança, abrindo-lhe o coração generoso. Ficamos sendo irmãos, ligados pelo mesmo laço de infortúnio, presos pelo mesmo destino. O que nunca pude descobrir foi o motivo da profunda ojeriza que tinha D. Rosa pela pequena. Era inexplicável aquela maldade. Rita era de uma doce e comovedora humildade. Vivia sempre no interior da casa muito esquiva e medrosa. No doméstico, apesar dos seus poucos anos, mostrava-se como se fora velha e experimentada serviçal. Trazia tudo a tempo e a hora, evitando ser mandada e procurando timidamente agradar a todos e não ser repreendida (Prata, 1953, p.22).

Ao rememorar as hostilidades vivenciadas pela menina Rita, o jovem médico Bento avalia, por meio da escrita de Ranulpho Prata - assim como tantos outros escritores brasileiros do difundido romance social de 1930 -, a importância de se conhecer a vida do país, como resultado do exame da questão social. Maria Stella Bresciani (2010, p.187-214) já refletiu com propriedade a respeito dessa vontade de conhecer o país, exercício de estratégia política difundida no início do século passado. A discussão está fundamentada no debate político de pensadores como Alberto Torres, que propôs aos intelectuais brasileiros o encontro com o Brasil real, na década de 1910. Na seguinte, respectivamente em 1928 e 1927/1929, surgem Retrato do Brasil: ensaio sobre a tristeza brasileira, de Paulo Prado (1997), e O turista aprendiz, de Mário de Andrade (2002), livros que circunscrevem a ideia da 'realidade nacional'. 
Os marginalizados são os que experimentaram as piores situações de privações, exauridos pela maldade da vida privada de direitos sociais e políticos mínimos. Essas classes pobres e suas condições de vida evidenciadas no contexto da industrialização das primeiras décadas do século passado tornaram-se instrumentos retóricos ficcionais de alguns romances nordestinos publicados na década 1930. Não obstante, a ideia de que resolução não seja necessariamente resignação aos problemas da vida, como pode ser conferido pelo leitor no romance Cacau (1934), de Jorge Amado, em que o personagem central, Sergipano, torna-se um revolucionário ao longo da narrativa; observa-se outra opção de saída para os problemas dos pobres por meio da tese do marxismo exposta pelo escritor baiano. A revolta torna-se então uma postura adequada, ou melhor, a única, para os pobres. Há autores também, como é o caso de Amando Fontes, que escreveu Os corumbas (1933) - livro premiado pela crítica e pelo público -, que propunham a não utilização de seus personagens como ferramentas da ideologia do escritor. Fontes advogava a exposição das dores e das lutas do povo brasileiro, mas sem tomar partido, pois acreditava que era uma postura questionável ao ofício do romancista (Lima, 2010). Os dois autores passam ao longe da postura estética e política de Ranulpho Prata, uma vez que a sugestão política de tratar os pobres com generosidade ou caridade parece inapropriada para Amando Fontes e Jorge Amado.

É o decênio do romance social e das intensificações das lutas políticas por direitos trabalhistas. Pouco conveniente seria assumir o viés da resignação estoica que ainda estava em vigor, associado à linha teórica do pensamento católico ao qual Prata se vinculou na década de 1920. É certo que era um problema central em um Brasil posterior ao golpe de 1930, em que os direitos sociais da grande maioria estavam agrilhoados aos ditames da ínfima fração da sociedade que explorava a mão de obra de forma irrestrita, o que trouxe a lume o papel de se pensar os dilemas dos marginalizados.

Em relação a isso, os romances dos autores nordestinos são essenciais para o debate profícuo a respeito das figurações de personagens, pois constroem sociedades idealizadas ou imaginadas, ao tocar o sensível (Rancière, 2009, p.15). E mais, por fornecer, em sua retórica, um projeto político que se torna material imprescindível na análise do historiador, ou mesmo do leitor que pretende observar aquilo que o escritor Orhan Pamuk nomeia de a "segunda vida" que o romance proporciona. Pois, "os romances revelam cores e complexidades de nossa vida e são cheios de pessoas, rostos e objetos que julgamos conhecer" (Pamuk, 2011, p.9).

\section{Considerações finais}

A análise da 'vida', proposta por Ranulpho Prata, parte tão somente dos sofrimentos infligidos pelos problemas da pobreza, da doença e do abandono. Essa tríade que une a vida das duas crianças, na óptica do escritor, tende sempre a fazer parte da história humana. Não é por acaso que o jovem Bento, ao tornar-se médico, trabalha em um leprosário; logo afirma insistentemente sua tese a respeito dos sofrimentos como oriundos da interferência divina. O mesmo ocorre agora na voz do escritor, que na mesma perspectiva de sua fala na conferência na seção do Centro Dom Vital, atesta a interferência divina nos sofrimentos. Ou, até mesmo, na biografia da jovem Marie Bashkirtseff (1948, p.162), que, ao escrever no diário - já em estado febril - a respeito da descrença veemente quanto à benevolência divina -, 
dizia que se o Deus ao qual ela amava realmente existisse, o mundo seria outro. Deus não ouvia as suas preces à noite, e mesmo assim, ela rezava penitentemente.

Para Ranulpho Prata, essa atitude da artista revela a não compreensão do sofrimento e do papel divino perante as tragédias que todos vivenciam. Visto que a naturalização da resignação impera como estratégia, pode explicar a vida que tanto Ranulpho deseja compreender através dos escritos ficcionais e também da filiação política ao pensamento do Centro Dom Vital.

Ao mesmo tempo, sua proposta política e estética impossibilita a ação, como apropriadamente realçou Hannah Arendt ao discorrer a respeito de outro sentimento tão importante quanto o sofrimento, que é a compaixão, chegando à conclusão próxima a de Ranulpho Prata. Segundo Arendt (2008, p.23), os dois sentimentos carregam forte carga de adesão, igualmente, uma força inquestionável de passividade que paralisa qualquer ação, ou mesmo qualquer saída para os reveses da vida política.

\section{NOTAS}

${ }^{1}$ Para o acervo ficcional e ensaístico do escritor, ver Prata (1918; 1925a; 1925b; 1934).

${ }^{2}$ Pouco se escreveu a respeito desse autor. Existe, portanto, um campo a ser explorado quanto à produção ficcional de intelectuais associados ao Centro Dom Vital. Como fruto recente da historiografia, cito dois trabalhos que versam sobre problemas referentes à escrita de Ranulpho Prata: Pereira (2008) e Bueno (2006).

${ }^{3} \mathrm{O}$ escritor Alberto Rangel foi o primeiro escritor do Norte do país a definir a Amazônia como inferno, no aclamado romance Inferno verde (1927).

${ }^{4} \mathrm{O}$ sentido hebraico do sacrifício é apontado por Mauss e Hubert (2005) como uma dádiva a Deus. Também se relaciona com a consagração, ou seja, uma passagem do domínio comum ao religioso.

${ }^{5}$ A compaixão é um sentimento político recorrente nos jogos de poder. Na literatura que versa sobre as classes pobres tornou-se uma arma retórica eficiente. Esse sentimento foi analisado com propriedade nas reflexões de Bresciani (2006), Starobinski (2007) e Seligmann-Silva (2009).

\section{REFERÊNCIAS}

AMADO, Jorge.

Cacau. Rio de Janeiro: Ariel. 1934.

ANDERSON, Julie; SHAKLETON, Emma.

The art of medicine. Chicago: Chicago University Press. 2011.

ANDRADE, Mário de.

O turista aprendiz. Belo Horizonte: Itatiaia. 1.ed. 1927/1929. 2002.

ARENDT, Hannah.

Homens em tempos sombrios. Tradução Denise Bottmann. Posfácio Celso Lafer. São Paulo: Companhia das Letras. 2008.

BARRETO, Afonso Henriques de Lima.

Recordações do escrivão Isaías Caminha. São Paulo: Ática. 1.ed. 1909. 1995.

BARRETO, Afonso Henriques de Lima. Correspondência. Tomo 2. Prefácio B. Quadros [Antonio Noronha Santos]. São Paulo: Brasiliense. 1961a.
BARRETO, Afonso Henriques de Lima. Marginália: artigos e crônicas. São Paulo: Brasiliense. 1961b.

BARTHES, Roland.

O efeito de real. In: Barthes, Roland et al.

Literatura e realidade: que é o realismo?

Apresentação Tzvetan Todorov. Tradução Teresa Coelho. Lisboa: Dom Quixote. p.87-97. 1984.

BASHKIRTSEFF, Maria.

Diario de mi vida. Buenos Aires: Espasa-Calpe. 1948.

BÍBLIA SAGRADA.

Nova versão internacional. São Paulo: Fôlego. 2007.

BERNARD, Claude.

Introduction à l'étude de la médecine expérimentale. Paris: Baillière. Disponível em: http://www. gutenberg.org/catalog/world/readfile?fk_ files=1503245. Acesso em: 30 ago. 2013. 1865 . 
BRESCIANI, Maria Stella Martins.

Projetos políticos nas interpretações do Brasil da primeira metade do século XX. Revista de História, São Paulo, edição especial, p.187-214. 2010.

BRESCIANI, Maria Stella Martins.

Literatura e cidade. In: Cardoso, Selma Passos; Pinheiro, Eloísa Petti; Corrêa, Elyane Lins (Org.). Arte e cidade: imagens, discursos e representações. Salvador: EdUFBA. p.9-40. 2008.

BRESCIANI, Maria Stella Martins. O charme da ciência e a sedução da objetividade: Oliveira Vianna entre intérpretes do Brasil. São Paulo: EdUnesp. 2007.

BRESCIANI, Maria Stella Martins. A compaixão pelos pobres no século XIX: um sentimento político. In: Seligmann-Silva, Márcio (Org.). Palavra e imagem: memória e escritura. Chapecó: Argos. p.91-126. 2006.

BRESCIANI, Maria Stella Martins. Identidades inconclusas no Brasil do século XIX: fundamentos de um lugar-comum. In: Bresciani, Stella; Naxara, Márcia (Org.). Memória $e$ (res)sentimento: indagações sobre uma questão sensível. Campinas: Editora da Unicamp. p.403-429. 2004.

BRESCIANI, Maria Stella Martins.

Metrópoles: as faces do monstro urbano (as cidades no século XIX). Revista Brasileira de História. São Paulo, v.5, n.8-9, p.35-68, 1985.

BUENO, Luís.

Uma história do romance de 30. Campinas: EdUsp; Editora da Unicamp. 2006.

CABRAL, Jacqueline Ribeiro.

Sacramentada pela fé: discurso católico sobre a ciência no Brasil do século XX (1921-1942). Tese (Doutorado) - Programa de Pós-graduação em História das Ciências e da Saúde, Casa de Oswaldo Cruz, Fiocruz, Rio de Janeiro. 2011.

CAMPOS, Cleomenes.

Humildade. São Paulo: Companhia Editora Nacional. 1931.

COUTO, Miguel.

No Brasil só há um problema nacional: a educação do povo. Rio de Janeiro: Tipografia do Jornal do Commercio. 1933.

COUTO, Miguel.

Seleção social no Brasil. In: Miguel Couto. A medicina e a cultura. v.1. Rio de Janeiro: Oscar Mano. p.80-112. 1932.

CUNHA, Euclides da.

Os sertões. Rio de Janeiro: Francisco Alves;

Publifolha. 2000.
DE DECCA, Edgar.

O nascimento das fábricas. São Paulo: Brasiliense. 1996.

FARIA, Daniel.

O bestiário do Brasil contemporâneo: figurações de desumanização em textos literários. In:

Naxara, Márcia; Marson, Izabel; Brepohl, Marion (Org.). Figurações do outro. Uberlândia: EdUfu. p.351-371. 2009.

FAURE, Olivier.

O olhar dos médicos. In: Corbin, Alan (Dir.).

História do corpo. Tradução João Batista Kreuch, Jaime Clasen. Petrópolis: Vozes. p.13-55. 2008.

FIGUEIREDO, Jackson de.

Jackson de Figueiredo. Gazeta de Notícias, Aracaju, 14 out. 1925. In: Prata, Ranulpho. A renascença das letras em França. Aracaju: José Lins de Carvalho. p.91. 1926.

FIGUEIREDO, Jackson de.

Humilhados e luminosos. Rio de Janeiro: Anuário do Brasil; Porto: Renascença Portuguesa. 1921.

FIGUEIREDO, Jackson de.

Pelo Brazil. Muzambinho: Typographia d'O Muzambinho. 1917.

FONTES, Amando.

Os corumbas. Rio de Janeiro: Livro Vermelho. 1933.

HERSCHMANN, Micael M.

A arte do operatório: medicina, naturalismo e positivismo, 1900-1937. In: Herschmann, Micael M. A invenção do Brasil moderno: medicina, educação e engenharia nos anos 20-30. Rio de Janeiro: Rocco. p.43-65. 1994.

LEUJEUNE, Philippe.

Diários de garotas francesas no século XIX: constituição e transgressão de um gênero literário. Tradução Simone Miziara Frangella. Cadernos Pagu, Campinas, n.8-9, p.99-119. 1997.

LIMA, Cleverton Barros de.

Imagens do povo: política e literatura na obra de Amando Fontes. Dissertação (Mestrado) - Instituto de Filosofia e Ciências Humanas, Universidade Estadual de Campinas, Campinas. 2010.

LIMA, Cleverton Barros de.

Figuras da exclusão na escrita do romance social brasileiro de 1930. LL Journal, New York, v.4, n.2. Disponível em: http://ojs.gc.cuny.edu/index. php/lljournal/article/view/512. Acesso em: 31 maio 2009. 2009.

LOPREATO, Christina da Silva Roquette. O espírito da revolta: a greve geral anarquista de 1917. São Paulo: Annablume; Fapesp. 2000. 
MACHADO, Dyonelio.

O louco do Cati. São Paulo: Planeta. 2003.

MAUSS, Marcel; HUBERT, Henri.

Sobre o sacrifício. Tradução Paulo Neves. São Paulo: Cosac Naify. 2005.

NAXARA, Márcia Regina Capelari.

Estrangeiro em sua própria terra: representações do brasileiro, 1870-1920. São Paulo: Annablume. 1998.

PAMUK, Orhan.

O romancista ingênuo e o sentimental. Tradução Hildegard Feist. São Paulo: Companhia das Letras. 2011.

PEREIRA, Alessandro Alberto Atanes.

História e literatura no porto de Santos: o romance de identidade portuária 'Navios iluminados'.

Dissertação (Mestrado) - Faculdade de Filosofia, Letras e Ciências Humanas, Universidade de São Paulo, São Paulo. 2008.

PEREIRA, Maria Helena Monteiro da Rocha. Estudos de história da cultura clássica. v.1. Lisboa: Calouste Gulbenkian. 1993.

PRADO, Paulo.

Retrato do Brasil: ensaio sobre a tristeza brasileira. São Paulo: Companhia das Letras. 1.ed. 1928. 1997.

PRATA, Ranulpho.

Navios iluminados. São Paulo: Scritta. 1.ed. 1937. 1996.

PRATA, Ranulpho.

Carta de Ranulpho Prata a Lima Barreto.

Jan. 1921. In: Barreto, Afonso Henriques de Lima. Correspondência. Tomo 2. Prefácio B. Quadros [Antonio Noronha Santos]. São Paulo: Brasiliense. p.245. 1961.

PRATA, Ranulpho.

Dentro da vida: narrativa de um médico de aldeia. São Paulo: Clube do Livro. 1.ed. 1922. 1953.

PRATA, Ranulpho.

Lampião. Rio de Janeiro: Ariel. 1934.

PRATA, Ranulpho.

Do sofrimento, caminho da perfeição.

Conferência realizada em 15 ago. 1933.

(Biblioteca Pública Epifânio Dória, Aracaju). 1933.

PRATA, Ranulpho.

A renascença das letras em França. Aracaju: José Lins de Carvalho. 1926.

PRATA, Ranulpho.

A longa estrada. Rio de Janeiro: Anuário do Brasil. 1925a.
PRATA, Ranulpho.

O lírio na torrente. Rio de Janeiro: Anuário do Brasil. 1925b.

PRATA, Ranulpho.

O triunfo. Rio de Janeiro: Revista dos Tribunais. 1918.

RANCIÈRE, Jacques.

A partilha do sensível: estética e política.

Tradução Mônica Costa Netto. São Paulo: EXO

Experimental; Editora 34. 2009.

RANGEL, Alberto.

Inferno verde: scenas e scenários do Amazonas. Tours: Arrault. 1927.

RICOEUR, Paul.

A metáfora viva. Tradução Dion Davi Macedo. São Paulo: Loyola. 2000.

ROMANO, Roberto.

Conservadorismo romântico: origem do totalitarismo. São Paulo: Edunesp. 1997.

SCLIAR, Moacyr.

Literatura e medicina: o território partilhado. Cadernos de Saúde Pública, Rio de Janeiro, v.16, n.1, p.245-248. 2000.

SECRETARIA...

Secretaria Municipal de Saúde do Rio de Janeiro. Biblioteca da Saúde. Biografia das unidades de saúde. Biografia de Miguel Couto. Disponível em: http://www.sms.rio.rj.gov.br/servidor/cgi/public/ cgilua.exe/web/templates/htm/v2/view.htm?inf oid=1057 \&editionsectionid=110. Acesso em: 30 ago. 2013. s.d.

SELIGMANN-SILVA, Márcio.

Para uma crítica da compaixão. São Paulo: Lumme. 2009.

SEVCENKO, Nicolau.

Literatura como missão: tensões sociais e criação cultural na Primeira República. São Paulo: Companhia das Letras. 2003.

SONTAG, Susan.

Doença como metáfora: Aids e suas metáforas. Tradução Rubens Figueiredo, Paulo Henriques Britto. São Paulo: Companhia das Letras. 2007.

STAROBINSKI, Jean.

Largesse. Paris: Gallimard. 2007.

ZOLA, Émile.

Thérèse Raquin. Tradução Sergio Flaksman.

São Paulo: Peixoto Neto. 1.ed. 1867. 2007.

ZOLA, Émile.

Do romance. Tradução Plínio Augusto Coelho. São Paulo: Imaginário; Edusp. 1995.

ZOLA, Émile.

Le roman experimental. Paris: Gallimard. 1971. 